\title{
Liderança em Resorts: um estudo dos estilos praticados no Brasil
}

\section{Liderazgo en Complejos Hoteleros: un estudio de los estilos practicados en Brasil}

\author{
Leadership in Resorts: a study of styles practiced in Brazil
}

\author{
Thaís de Almeida Giuliani ${ }^{1}$ \\ Eduardo de Camargo Oliva ${ }^{2}$
}

\begin{abstract}
Resumo
O segmento da Hotelaria é profundamente afetado pelo comportamento de seus líderes e suas características pessoais, e especialmente, pela maneira como influenciam seus seguidores a alcancarem este resultado. Sendo assim, o presente artigo tem como objetivo geral identificar e analisar os estilos de liderança praticados nos resorts do Brasil. Buscou ainda mapear no grupo de gestores, quais possuem o estilo de liderança transacional e transformacional pela opinião dos próprios gestores e de seus liderados. Para tanto, como método de pesquisa foi realizado um estudo exploratório descritivo de natureza quantitativa e qualitativa, junto a 169 funcionários de 14 resorts certificados pela Associação Brasileira de Resorts do Brasil de todas as regiões do país. Os dados coletados através da pesquisa quantitativa foram tratados por meio da técnica estatística de análise fatorial confirmatória, bem como de técnicas estatísticas de análise de frequência e variância. Já os dados obtidos através da pesquisa qualitativa foram analisados por meio da técnica de análise do discurso - Focus Group. Os resultados da pesquisa quantitativa demonstraram que o estilo de liderança predominante praticado nos resorts do Brasil é o Transformacional. Já os resultados da pesquisa qualitativa apresentaram-se de forma contrária e demonstraram que o estilo de liderança predominante é o Transacional. Esta discrepância entre os resultados das duas pesquisas levou à busca de um entendimento maior acerca das possíveis causas, chegando à conclusão de que a desejabilidade social pode explicar a diferença de opinião dos líderes e liderados participantes da pesquisa quantitativa.
\end{abstract}

Palavras-Chave: Estilos de liderança. Resorts. Liderança Transformacional e Liderança Transacional.

\footnotetext{
${ }^{1}$ Mestre em Administração pela Universidade Municipal de São Caetano do Sul (USCS). Graduada em Turismo pela Universidade Anhembi Morumbi (UAM). Brasil. E-mail: thaisgiuliani@ hotmail.com.

2 Doutor em Administração pela Universidade de São Paulo (USP). Mestre em Administração pela Pontifícia Universidade Católica de São Paulo (PUC-SP). Graduado em Administração pela USCS. Professor do Programa de Pós-Graduação em Administração da USCS. Brasil. E-mail: eduardo.oliva@ uscs.edu.br.
} 


\begin{abstract}
Resumen
El segmento de la hospitalidad está profundamente afectada por el comportamiento de sus líderes y sus características personales, y especialmente por la forma en que influyen en sus seguidores para lograr este resultado. Por lo tanto, este artículo tiene como objetivo identificar y analizar los estilos de liderazgo se practica en los centros turísticos de Brasil. También ha tratado de asignar el grupo de directivos, que tienen el estilo de liderazgo transaccional y transformacional de la opinión de los propios gestores y sus subordinados. Para ello, como un método de investigación se llevó a cabo un estudio exploratorio de indicadores cuantitativos y cualitativos, con los 169 empleados de 14 estaciones certificadas por la Asociación Brasileña de Resorts de Brasil en todo el país. Los datos recogidos a través de la investigación cuantitativa fueron tratados mediante la técnica estadística del análisis factorial confirmatoria, y las técnicas estadísticas de análisis de varianza y frecuencia. Dado que los datos obtenidos a través de la investigación cualitativa se analizaron mediante la técnica de análisis del discurso - Focus Group. Los resultados de la investigación cuantitativa mostró que el estilo dominante de liderazgo se practica en los centros turísticos de Brasil es el transformacional. Los resultados de la investigación cualitativa se presentan en forma contraria y demostraron que el estilo dominante de la dirección es transaccional. Esta discrepancia entre los resultados de dos encuestas llevó a la búsqueda de una mayor comprensión de las causas posibles, llegando a la conclusión de que la deseabilidad social puede explicar la diferencia de los líderes de opinión y los participantes de la investigación cuantitativa.
\end{abstract}

Palabras clave: estilos de liderazgo. Resorts. Liderazgo transformacional y liderazgo transaccional.

\begin{abstract}
The hotel industry is deeply affected by the behavior of its leaders and their personal characteristics, and especially by the way the leader influences its followers to achieve the goal. Therefore, this paper has a general objective to identify and analyze the styles of leadership practiced in Brazilian resorts. In addition, this dissertation identified the group of managers, which possess the transactional and transformational leadership considering the opinion of the very managers and leaders. Hence, as the approach for the research was carried out an exploratory descriptive study of qualitative and quantitative nature, it included 169 staff members of 14 resorts certified by the Brazilian Association of Resorts of Brazil of all the regions of the country. The data collected through the quantitative research were treated by means of the statistical technique of confirmatory factor analysis, as well as statistical techniques of frequency analysis and variance. The data obtained through the qualitative research were analyzed by means of the technical analysis of speech - Focus Group. The results of the quantitative research showed that the predominant leadership style practiced in Brazilian resort is the Transformational. In the other hand, the results of the qualitative research presented itself the opposite and showed that the predominant leadership style is Transacional, besides showing difference in opinion within the professionals researched, considering the genre. This discrepancy between the results of two surveys led to the search for a greater understanding of the possible causes, reaching the conclusion that social desirability may explain the difference of opinion leaders and participants of the quantitative research.
\end{abstract}

Keywords: Styles of leadership, Resorts, Leadership Transformational and Leadership Transactional. 


\section{TURISMO EM ANÁLISE}

\section{Introdução}

No campo do Comportamento Organizacional, o tema liderança é um assunto complexo, controverso e desafiador, pois o seu conceito tem sido alvo de várias interpretações e definições no último século. (BASS 1990).

Os conceitos, principalmente na primeira metade do século passado demonstravam que as pessoas eram vistas como máquinas e os gestores das organizações não as enxergavam como seres complexos com necessidades individuais. Mais contemporaneamente observou-se um avanço na ampliação da consideração das pessoas como realizadoras das estratégias organizacionais. (STEFANO et al. 2006; ALBUQUERQUE E LEITE, 2010).

De certa forma os líderes começam a entender a importância de se investir e se preocupar com os colaboradores e assim tentar garantir o comprometimento das equipes na busca de melhores resultados.

Segundo Kotter (1992), a liderança teve ao longo da história e com toda a probabilidade continuará tendo uma importância significativa nos assuntos humanos, e de forma progressiva, também no âmbito organizacional.

Sendo assim, a seleção, o desenvolvimento e a promoção de pessoas para posições de liderança passou a ganhar destaque. (GONÇALVES, 2008). Na atualidade, os conceitos sobre liderança propõem a segurança servidora, na qual o líder deveria apoiar e fortalecer seus seguidores. As implicações desta nova postura para o setor hoteleiro são consideráveis, uma vez que o trabalho da liderança é decisivo para a prestação de um excelente serviço ao hóspede. (BROWNELL, 2010).

Segundo Brownell (2010), as organizações que trabalham com a hospitalidade, nas quais estão inseridos os hotéis, influenciam a sociedade em que atuam, de forma a refletir nas normas e nos valores das pessoas que nelas trabalham. A indústria da hospitalidade funciona em rede com diversos parceiros externos. Internamente destacam-se os gestores de área dos empreendimentos, com seus comportamentos, características pessoais e um papel determinante na maneira de tratar as pessoas nesse segmento. Clark, Hartline e Jones (2008) complementam esta questão, quando relatam que um dos desafios permanentes da indústria 


\section{TURISMO EM ANÁLISE}

hoteleira é proporcionar níveis consistentes de qualidade de serviço, através da hospedagem de seus clientes.

Além de se tornar referência na qualidade do serviço prestado, a indústria hoteleira configurase como um dos mais importantes elos da cadeia de serviços turísticos, onde movimenta grande parte da economia dos países voltados a esta atividade, com relevantes contribuições na geração de renda e empregos. Em 2011, somente os meios de hospedagem geraram cerca de 300.000 empregos diretos. (INSTITUTO BRASILEIRO DE GEOGRAFIA E ESTATÍSTICA - IBGE, 2012).

Este número tende a melhorar nos próximos anos de forma significativa, tornando o Brasil um país com grandes potencialidades turísticas, principalmente com a chegada de grandes eventos como a Copa do mundo de 2014 e as Olimpíadas de 2016.

Por este motivo, pesquisar os estilos de liderança no setor hoteleiro, mais especificamente nos hotéis tipo Resorts, segundo classificação oficial do Instituto Brasileiro de Turismo EMBRATUR torna-se um fator de relevância.

Com base nos pressupostos previamente indicados, pretende-se com esta pesquisa alcançar o objetivo geral de identificar e analisar os estilos de liderança praticados nos resorts do Brasil, certificados pela Associação Brasileira de Resorts.

A partir do alcance do objetivo geral, esta pesquisa apresenta os seguintes objetivos específicos:

1) Mapear no grupo de gestores, quais possuem o estilo de liderança transacional e transformacional pela opinião dos próprios gestores dos departamentos;

2) Mapear o grau de liderança transacional e transformacional pela opinião dos funcionários que respondem diretamente a esses líderes;

3) Comparar os estilos de liderança pela opinião dos líderes e liderados.

A pesquisa torna-se relevante pelo fato de que o Brasil está vivendo um momento crucial para a economia e desenvolvimento do Turismo, o que faz das diversas atividades relacionadas ao Turismo, como a Hotelaria, prioridade nos investimentos e melhorias. De acordo com Brasil (2012), a Copa do Mundo de 2014 estima agregar cerca de $\mathrm{R} \$ 183$ bilhões ao PIB do Brasil até o ano de 2019, conforme mostra a figura 1: 


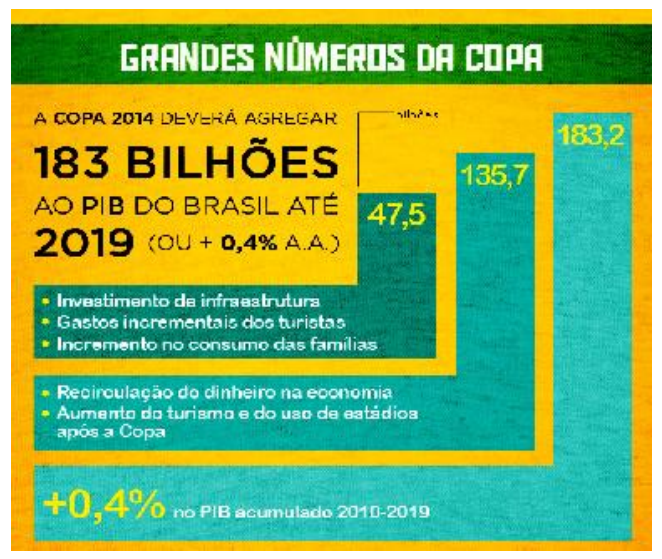

Figura 1 - Grandes números da Copa

Fonte: Brasil (2012).

Estes dados representam um crescimento relevante para o país, visto que em 2007, as atividades características do Turismo geraram uma renda de $\mathrm{R} \$ 92,7$ bilhões, o que corresponde a 3,6\% do valor adicionado da economia brasileira e 5,4\% do setor de serviços. (INSTITUTO BRASILEIRO DE GEOGRAFIA E ESTATÍSTICA - IBGE, 2010).

A presente pesquisa foi realizada com profissionais que trabalham nos resorts certificados pela Associação Brasileira de Resorts. A Associação possui atualmente 44 Resorts certificados em diversas regiões do Brasil.

Segundo a Associação Brasileira de Resorts (2011), entende-se por Resort um empreendimento hoteleiro de alto padrão em instalações e serviços, fortemente voltado para o lazer em área de amplo convívio com a natureza, no qual o hospede não precisa se afastar para atender suas necessidades de conforto, alimentação, lazer e entretenimento.

A escolha por este tipo de empreendimento hoteleiro é justificado pela amplitude de sua estrutura e serviços, assim como pelo nível de exigência de seus clientes em relação ao atendimento, o que exige de seus funcionários uma melhor qualificação e competência para servir de forma que atenda as expectativas dos clientes. 


\section{Liderança}

A liderança é um assunto em constante evolução. Definir o fenômeno liderança já originou diversas posições conceituais diferentes, sendo muitas delas contraditórias ou reflexões de uma tendência passageira, tanto para área gerencial quanto para a área acadêmica. (BENNIS; NANUS, 1988).

Um levantamento feito nos trabalhos pesquisados entre a década de 50 e a década de 80 , apontam os diferentes pontos de vista sobre o conceito de liderança, conforme demonstra o quadro 1 a seguir. (YUKI, 1989 apud BERGAMINI, 1994):

\begin{tabular}{|l|l|}
\hline \multicolumn{1}{|c|}{ Época - Autores } & \multicolumn{1}{c|}{ Conceito } \\
\hline Hemphill e Coons - 1957 & $\begin{array}{l}\text { "Liderança é o comportamento de um indivíduo } \\
\text { quando está dirigindo as atividades de um grupo em } \\
\text { direção a um objetivo comum". }\end{array}$ \\
\hline Janda -1960 & $\begin{array}{l}\text { "Liderança é um tipo especial de relacionamento de } \\
\text { poder caracterizado pela percepção dos membros do } \\
\text { grupo no sentido de que, o outro membro do grupo } \\
\text { tem o direito de prescrever padrões de comportamento } \\
\text { na posição daquele que dirige no que diz respeito à } \\
\text { sua atividade na qualidade de membro do grupo". }\end{array}$ \\
\hline Jacobs - 1970 & $\begin{array}{l}\text { "Liderança é uma interação entre pessoas na qual uma } \\
\text { apresenta informação de um tipo e de tal maneira que } \\
\text { os outros se tornam convencidos de que seus } \\
\text { resultados serão melhorados caso se comporte da } \\
\text { maneira sugerida ou desejada". }\end{array}$ \\
\hline Katz e Kahn - 1978 & $\begin{array}{l}\text { "Liderança é o incremento da influência sobre e acima } \\
\text { de uma submissão mecânica com as diretrizes } \\
\text { rotineiras da organização". }\end{array}$ \\
\hline Rouch e Behling - 1984 & $\begin{array}{l}\text { "Liderança é o processo de influenciar as atividades } \\
\text { de um grupo organizado na direção da realização de } \\
\text { um objetivo". }\end{array}$ \\
\hline
\end{tabular}

Quadro 1 - Conceitos de liderança

Fonte: adaptado de Bergamini (1994, p. 14).

Ao longo dessas definições, é possível identificar algo em comum entre elas. Segundo Bergamini (1994), elas conservam o denominador comum de que a liderança está ligada a um 
fenômeno de aplicação individual ou grupal, e destaca um processo de influenciação exercido de forma intencional por parte do líder sobre seus colaboradores.

O entendimento de que o processo de influência está relacionado ao fenômeno da liderança, é também confirmado por Bass (1990), ao descrever que o conceito de influência reconhece que os indivíduos sejam diferentes uns aos outros e que tal fato implica em um relacionamento recíproco entre os líderes e seus seguidores, mas não por dominação ou controle e sim por meio do seu próprio exemplo.

As mais recentes abordagens da liderança apresentam os conceitos de liderança transacional e transformacional. Segundo Bento (2008), Burns (1978) foi o primeiro a chamar a atenção para estes conceitos, onde ele afirma que a liderança transacional e a transformacional se baseavam em "relações" e "poder".

Tendo estudado líderes como Franklin D. Roosevelt, Nikolai Lenine, Luís XVI, e John F. Kennedy, Burns (1978) desenvolveu uma taxonomia de liderança que caracterizam os líderes como "transacional" ou "transformacional". Ele descreveu os líderes transacionais como aqueles de quem parte a iniciativa em fazer contato com os outros com a finalidade de transacionar aspectos de interesse que tenham valor para os dois lados. Por outro lado, a liderança transformacional ocorre quando as pessoas decidem se envolver com outros indivíduos, de tal forma que líderes e colaboradores elevam os níveis de motivação e moral. (BURNS, 1978). Reconhece-se a eficácia de ambas as formas de liderança e conclui-se que a liderança transformacional, com uma forte dimensão moral, foi associada a uma liderança eficaz e que em tempos de instabilidade foi mais duradoura do que a do modelo transacional. (BURNS, 1978 apud BROWN; REILLY, 2008).

Segundo Bass (2008), a liderança transformacional foi mencionada pela primera vez, por Downton (1973). Já Burns (1978) dedicou-se a investigar os dois estilos como opostos. Mais tarde Bass (2008) demonstrou de forma empirica que os dois estilos de liderança são duas dimensões correlacionadas positivamente e que a liderança transformacional acrescenta os efeitos da liderança transacional.

Sendo assim, pode-se afirmar que a liderança transacional é um processo de troca entre os líderes e liderados, baseado na recompensa. O líder transacional transmite suas expectativas 
quanto às metas e desempenho de seus liderados, assim como sua relação com as recompensas. Para Smith (2005) o líder acompanha o desempenho de seus seguidores e propõe ações corretivas quando necessário. Seguindo o mesmo raciocínio, Burns (1978) comenta que a liderança transacional ocorre quando uma pessoa toma a iniciativa de estabelecer contato com as outras com o objetivo de trocar bens de valor, esses bens podem ser de ordem econômica, política ou psicológica. Bass (2008) corrobora com esta ideia e afirma ainda que um líder é transacional quando ele recompensa seus funcionários com prêmios ao cumprirem com os objetivos acordados, mas ao mesmo tempo cobra e pune de forma excessivamente rígida quando não conseguem fazer o esperado. A Liderança Transacional enfatiza a troca que ocorre entre um líder e seus funcionários. Este intercâmbio envolve a direção do líder ou discussão mútua com os funcionários sobre os requisitos para alcançar os objetivos desejados. (BASS, 2008).

Já a liderança transformacional é baseada na mutualidade de propósito e na influência do líder no seguidor. A ação de liderança, neste caso, deve ocorrer em dupla direção a fim de estabelecer o clima de respeito ao outro de forma completa. (GONÇALVES, 2008). Burns (1978) diz que a liderança transformacional aumenta o nível de consciência dos funcionários sobre a importância e o valor dos resultados designados, bem como as formas de alcançá-los. Ele afirma ainda que esta liderança faz com que seus funcionários transcedam seus próprios interesses em nome da equipe e da organização. Bass (2008) complementa esse conceito quando menciona o fato de que o líder transformacional eleva o nível de maturidade de seus funcionários, bem como os engajam e motivam sem o uso do poder. Ele consegue transformar pessoas, grupos, organizações e até mesmo a sociedade.

Segundo Bass e Avolio (1997) apud Bergamini (2008), um líder transformacional difere do transacional não apenas por reconhecer as necessidades dos associados, mas pelo fato de buscar desenvolver as necessidades que vão desde um nível mais baixo para mais alto de maturidade. O quadro 3 apresenta algumas diferenças entre os dois estilos. 


\begin{tabular}{|c|c|}
\hline Liderança Transacional & Liderança Transformacional \\
\hline Desenvolve a necessidade de terminar tarefas. & Desenvolve a necessidade de um significado. \\
\hline Desenvolve a preocupação em ganhar dinheiro. & Desenvolve a preocupação com propósitos. \\
\hline Poder e Posição. Política e Vantagens. & Valores, princípios éticos e morais. \\
\hline Voltada para resultados em curto prazo. & Voltada para o alcance de objetivos de longo prazo. \\
\hline Inspira-se no respeito às regras & Inspira-se no amor. \\
\hline $\begin{array}{l}\text { Apoia sistemas e estruturas que reforçam o } \\
\text { resultado. }\end{array}$ & Identifica e desenvolve talentos. \\
\hline $\begin{array}{l}\text { Segue o padrão de comportamento atendendo as } \\
\text { expectativas. }\end{array}$ & $\begin{array}{l}\text { Realiza o alinhamento de valores e objetivos } \\
\text { principais. }\end{array}$ \\
\hline Voltada para eficiência. & Voltada para eficácia. \\
\hline
\end{tabular}

Quadro 2 - Diferenças entre liderança transacional e liderança transformacional Fonte: adaptado de Covey (2002).

Ao analisar todos esses conceitos é possível observar que a principal diferença entre os dois estilos é que no transacional o líder consegue os resultados através de uma troca e que tanto o líder quanto seus funcionários estão mais preocupados com os seus próprios interesses. Isso não acontece na liderança transformacional, onde o líder consegue despertar em cada funcionário a motivação necessária para o alcance dos resultados almejados pela organização, transformando os interesses gerais como próprios de cada indivíduo. Isso é o que torna esse estilo tão fascinante e eficaz.

Por este motivo Brownel (2010), afirma que o estilo de maior relevância para os líderes que trabalham na indústria da hospitalidade é o transformacional. Isto porque este tipo de liderança mantém a colaboração entre as relações interpessoais, estabelecendo uma comunicação aberta, bem como o apoio à equipe e a responsabilidade de fornecer os recursos necessários para cumprir esta visão compartilhada. Na pesquisa de Carvalho, Silva e Zago (2011), a educação formal contribui de forma especial para a obtenção e a ampliação das competências gerenciais. Esses fatores são importantes para atingir melhores resultados neste tipo de segmento, onde está inserida a população estudada da presente pesquisa. 


\section{Procedimentos Metodológicos}

Este artigo foi desenvolvido por meio de uma pesquisa quantitativa e qualitativa, que utiliza o método de abordagem misto. Segundo Creswell (2010), a pesquisa de métodos mistos é uma abordagem da investigação que combina ou associa a forma quantitativa e qualitativa. Por isso é mais do que uma simples coleta e análise dos dois tipos de dados, pois trabalha o uso das duas abordagens em conjunto, de modo que a força geral deste tipo de estudo seja maior do que a da pesquisa quantitativa ou qualitativa isolada.

Foi realizada uma pesquisa exploratória descritiva, que tem como propósito proporcionar maior familiaridade com o problema, além de descrever as características de determinada população ou fenômeno. (GIL, 2010). O método pode ser considerado também exploratório, não pelo tema liderança, mas sim pelo segmento pesquisado. Não se encontram pesquisas acadêmicas sobre os estilos de liderança praticados na hotelaria no Brasil, somente no exterior, como Brownell (2010) e Freitas (2006). Uma parte do delineamento da pesquisa foi o levantamento, que proporciona a interrogação direta das pessoas, cujo comportamento se deseja conhecer. (GIL, 2010).

A amostra foi não probabilística, do tipo por conveniência. A população estudada foi composta por duas categorias de profissionais. Uma, envolveu os profissionais que atuam em cargos de liderança em resorts certificados pela Associação Brasileira de Resorts na posição funcional de gerente, supervisor e coordenador. Outra envolveu os colaboradores liderados por esses líderes que atuam nessas mesmas unidades.

Em relação ao procedimento de coleta de dados, para a pesquisa quantitativa os pesquisadores, contaram com o apoio da entidade Resorts Brasil, que enviou um e-mail solicitando o preenchimento da pesquisa para fins acadêmicos. O e-mail foi enviado aos Gerentes e Diretores Gerais de cada empreendimento com uma solicitação de devolução com o aceite da participação do resort na pesquisa. Além do convite da mesma entidade, os pesquisadores entraram em contato por telefone e e-mail com todos os departamentos de Recursos Humanos dos Resorts associados. Os resorts que aceitaram participar da pesquisa foram: 
A Tabela 1 demonstra o número de respondentes por resort pesquisado e a região em que está localizado.

\begin{tabular}{|l|c|c|c|}
\hline \multicolumn{1}{|c|}{ Resort } & Região & Frequência & Porcentagem \\
\hline Bourbon Atibaia & Sudeste & 20 & $11,83 \%$ \\
\hline Paradise Resort & Sudeste & 89 & $52,67 \%$ \\
\hline Royal Palm Plaza & Sudeste & 4 & $2,36 \%$ \\
\hline Casa Grande Hotel Resort & Sudeste & 17 & $10,06 \%$ \\
\hline Hotel Senac Campos do Jordão & Sudeste & 2 & $1,18 \%$ \\
\hline Hotel Senac Águas de São Pedro & Sudeste & 2 & $1,18 \%$ \\
\hline Bourbon Foz do Iguaçu & Sul & 6 & $3,56 \%$ \\
\hline Hotel Costão do Santinho & Sul & 2 & $1,18 \%$ \\
\hline Rio Quente Resorts & Centro Oeste & 2 & $1,18 \%$ \\
\hline Hotel Transamérica de Comandatuba & Nordeste & 12 & $7,11 \%$ \\
\hline Jatiuca Resort & Nordeste & 7 & $4,15 \%$ \\
\hline Beach Park Acqua Resorts & Nordeste & 2 & $1,18 \%$ \\
\hline Beach Park Suites Resorts & Nordeste & 2 & $1,18 \%$ \\
\hline Club Med Trancoso & Nordeste & 2 & $1,18 \%$ \\
\hline \multicolumn{1}{|c|}{ Total } & & 169 & $100 \%$ \\
\hline
\end{tabular}

Tabela 1 - Resort e região dos respondentes

Fonte: dados da pesquisa.

Como pode ser observado nessa tabela, dos 44 resorts certificados pela Resorts Brasil, 14 participaram da pesquisa, sendo 6 resorts da região Sudeste, 2 resorts da região Sul, 1 resort da região Centro Oeste e 5 resorts da região Nordeste. A maior concentração foi na região Sudeste com um total de 134 respondentes $(79,28 \%)$. Já a região Sul teve 8 respondentes $(4,74 \%)$. A região Nordeste teve um total de 25 respondentes ( 14,8\%). A menor concentração foi na região Centro Oeste com 2 respondentes $(1,18 \%)$. 
A coleta de dados seguiu o mesmo procedimento para todos os respondentes de todas as regiões do país. Os questionários foram respondidos através do autopreenchimento, de forma impressa e eletrônica, e foram desenvolvidos na ferramenta Survey Monkey, que também conta com a disponibilização do endereço URL para acesso direto no formato eletrônico.

$\mathrm{O}$ instrumento de coleta de dados utilizado na pesquisa foi o questionário Multifactor Leadership Questionnaire ${ }^{\circledR}$ - MLQ, (Questionário Multifatorial de Liderança) desenvolvido pelos autores Bass e Avolio (1990) apud Almeida (2004) e Dutra (2006). Este questionário tem se mostrado como um instrumento válido e confiável para medição dos comportamentos de liderança. (ANTONAKIS et al., 2003; TEPPER; PERCY,1994 apud BROWN; REILLY, 2008)

Em relação à análise dos dados, primeiramente na abordagem quantitativa, todo o tratamento estatístico foi realizado com o auxílio do software estatístico "Statistical Package for the Social Sciences” (SPSS), versão 17.0. Em primeiro lugar foi utilizada a técnica estatística de análise de frequência, com o objetivo de conhecer a opinião predominante da amostra em relação aos atributos da Liderança Transacional, e Transformacional. Optou-se por analisar as respostas dos líderes e liderados juntos, a fim de responder ao objetivo geral da presente pesquisa, bem como por conhecer a opinião semelhante dos participantes. Em seguida, para avaliar a diferença de opiniões dos líderes e seus liderados, medidas pelas pontuações obtidas pelas escalas do instrumento MLQ, procedeu-se à comparação das frequências para então se inferir qual estilo de liderança foi o predominante.

A abordagem qualitativa foi operacionalizada por meio da realização de Focus Group, que segundo Oliveira e Freitas (1998) é um tipo de entrevista em profundidade realizada em grupo que apresenta características definidas quanto à proposta, tamanho, composição e procedimentos de condução. O foco de análise é a interação dentro do grupo, onde os participantes influenciam uns aos outros através das respostas às ideias e colocações durante a discussão. Faz-se necessário a participação de um moderador e um observador para conduzir as questões apresentadas.

Para isso, primeiramente os pesquisadores convidaram, por meio de e-mail, dez profissionais da área considerados formadores de opinião do Estado de São Paulo, sendo cinco mulheres e 
cinco homens. Todos aceitaram o convite. Foram realizadas duas reuniões, sendo uma somente com os profissionais do sexo feminino e outra com os profissionais do sexo masculino. Esta divisão baseou-se no fato de que o Focus Group deve ser realizado com grupos homogêneos para melhor promover a discussão dos temas abordados, sendo o gênero um dos fatores discriminantes mais utilizados na formação desses grupos. Outra questão importante a ser definida na formação dos grupos é o tamanho. Nesta definição, deve-se ponderar para que o mesmo seja pequeno o suficiente para que todos tenham oportunidade de partilhar suas percepções e grande o suficiente para fornecer diversidade de percepções. Em função desses argumentos seguiu-se a recomendação de que cada grupo ficasse no intervalo de 5 a 10 participantes. (OLIVEIRA; FREITAS, 1998).

\section{Resultados}

Os resultados da presente pesquisa foram analisados pelas abordagens quantitativa e qualitativa. Em primeiro plano, são apresentados e analisados os resultados da pesquisa survey. Em seguida, são apresentados os resultados auferidos na pesquisa qualitativa, por meio da técnica aplicada do focus group (grupo focal).

\subsection{Pesquisa quantitativa}

A amostra desta pesquisa é constituída de 169 profissionais que trabalham nos resorts do Brasil e que ocupam cargos de diferentes níveis hierárquicos, sendo que do número total 68 respondentes $(40,3 \%)$ são considerados líderes e 101 respondentes $(59,7 \%)$ são considerados liderados.

Em relação à caracterização da amostra, a maioria dos respondentes é do sexo feminino $(63,3 \%)$ e compreendem as idades entre 20 e 40 anos (74\%). Já sobre o nível de escolaridade, a maioria dos respondentes $(49,10 \%)$ possui formação superior completa, embora o número de profissionais com formação colegial completo ou superior incompleto por si só contemple $36,7 \%$. Estes dados podem refletir o alto nível de exigência cultural e de formação que os profissionais do segmento hoteleiro devem ter para atender os diversos tipos de hóspedes em seus empreendimentos. Um dos critérios utilizados na seleção geral de um resort é a formação mínima do primário completo, para os cargos de limpeza e cozinha. Conforme o nível 
hierárquico aumenta, a exigência pode chegar à pós-graduação completa para cargos de gerência. Outra questão fundamental é que além da formação acadêmica, o conhecimento de outros idiomas é extremamente importante para os principais cargos dentro de um resort.

Como pode ser observado em Carvalho, Silva e Zago (2011), o aumento da educação formal para gestores de hotéis proporciona o desenvolvimento de competências especiais no trato com clientes, funcionários e proporciona o aumento da eficiência no trabalho.

Para apresentar a localização dos resorts participantes da pesquisa, distribuíram-se os empreendimentos na Tabela a seguir:

\begin{tabular}{|l|l|l|l|}
\hline Região & Resort Associado & Resort Respondente & Porcentagem Respondente \\
\hline Norte & 0 & 0 & $0 \%$ \\
\hline Nordeste & 27 & 5 & $18,51 \%$ \\
\hline Centro Oeste & 1 & 1 & $100 \%$ \\
\hline Sudeste & 13 & 6 & $46,15 \%$ \\
\hline Sul & 3 & 2 & $66,66 \%$ \\
\hline Total & 44 & 14 & - \\
\hline
\end{tabular}

Tabela 2 - Localização: resorts associados X resorts participantes

Fonte: dados da pesquisa.

A Tabela 2 demonstra que a região com o menor número de respondentes da pesquisa em comparação a amostra foi o Nordeste com 18,51\%. A região Centro Oeste, embora tenha um número pequeno de respondentes, conforme demonstra a tabela, obteve $100 \%$ de participação. A região Sul com 66,66\% também teve uma boa participação onde 2 dos 3 resorts certificados responderam a pesquisa. Por fim a região Sudeste, que obteve o maior número de respondentes, em comparação ao número de resorts associados, obteve a participação de $46,15 \%$.

Para responder ao objetivo geral da presente pesquisa, utilizou-se a análise de frequência para medir as assertivas do MLQ, conforme apresenta a Tabela 3. 


\begin{tabular}{|l|l|l|l|l|l|}
\hline Estilo de Liderança & $\begin{array}{l}\text { De modo } \\
\text { Algum }\end{array}$ & Raramente & Frequentemente & $\begin{array}{l}\text { Valor } \\
\text { Ausente }\end{array}$ & TOTAL \\
\hline Transformacional & $5,8 \%$ & $25,1 \%$ & $64,5 \%$ & $4,6 \%$ & $100 \%$ \\
\hline Transacional & $17,7 \%$ & $31,8 \%$ & $46,6 \%$ & $3,9 \%$ & $100 \%$ \\
\hline Laissez-faire & $55,9 \%$ & $26,2 \%$ & $13,3 \%$ & $4,6 \%$ & $100 \%$ \\
\hline
\end{tabular}

Tabela 3 - Distribuição percentual da análise compilada do estilo de liderança Fonte: dados da pesquisa.

Essa tabela mostra que 64,5\% dos respondentes afirmam que os líderes utilizam frequentemente os atributos da liderança transformacional durante o exercício de suas atividades, ao passo que $25,1 \%$ dos respondentes afirmaram que os líderes utilizam raramente estes atributos. Quanto à liderança transacional, 46,6\% afirmam que frequentemente os líderes utilizam os atributos relacionados a este estilo, em contrapartida 31,8\% raramente utilizam tais atributos.

Ao analisar o resultado desta comparação é possível inferir que o estilo de liderança predominante praticado nos resorts do Brasil, segundo a análise de frequência feita por meio dos dados coletados na pesquisa quantitativa, é o transformacional. Os dados foram analisados de forma conjunta, ou seja, líderes e liderados, o que pode- se deduzir que esta seja uma possível causa para a predominância deste estilo, visto que o líder tende a se classificar como gostaria ou deveria ser e não propriamente pelo o que realmente é.

Para identificar qual o estilo de liderança dos resorts pela visão dos líderes, procedeu-se à comparação das frequências para então se inferir qual estilo de liderança foi o predominante. Os resultados foram apresentados na Tabela 4. 


\begin{tabular}{|l|l|l|l|l|}
\hline Estilo & Raramente \% & $\begin{array}{l}\text { Algumas Vezes } \\
\%\end{array}$ & $\begin{array}{l}\text { Frequentemente } \\
\%\end{array}$ & Valores ausentes \% \\
\hline Transformacional & 6,5 & 13,5 & 73,7 & 6,1 \\
\hline Transacional & 31,4 & 18,6 & 44,5 & 5,2 \\
\hline
\end{tabular}

Tabela 4 - Estilo de liderança pela visão dos líderes Fonte: dados da pesquisa.

De acordo com os dados nessa tabela, $73,7 \%$ dos líderes questionados afirmam utilizar frequentemente os atributos de liderança transformacional. Este valor demonstra que o estilo de liderança predominante nos resorts do Brasil pela visão dos líderes é o Estilo Transformacional.

Este resultado apresenta-se de forma positiva, pois corrobora com a afirmação de Brownell (2010) quando diz que o estilo de maior relevância para os líderes que trabalham na indústria da hospitalidade é o transformacional.

Para identificar qual o estilo de liderança dos resorts pela visão dos liderados, procedeu-se à comparação das frequências para então se inferir qual estilo de liderança foi o predominante. Os resultados foram apresentados na Tabela 5.

\begin{tabular}{lllll}
\hline Estilo & Raramente \% & Algumas Vezes \% & Frequentemente\% & Valores ausentes \% \\
& & & & \\
\hline Transformacional & 21,468 & 21,303 & 54,107 & 3,122 \\
\hline Transacional & 32,877 & 21,644 & 42,831 & 2,648 \\
\hline
\end{tabular}

Tabela 5 - Estilo de liderança pela visão dos liderados

Fonte: dados da pesquisa.

Observa-se que $54,1 \%$ dos liderados questionados afirmam que seus líderes utilizam frequentemente os atributos de liderança transformacional. Este valor demonstra que o estilo de liderança predominante nos resorts do Brasil pela visão dos liderados é o Estilo 
Transformacional, embora houvesse um equilíbrio maior entre os resultados de ambos os estilos. Se comparar estes dados ao resultado pela visão dos líderes, é possível inferir que os liderados demonstram em menor proporção a predominância do estilo transformacional. Eles provavelmente estejam representando de forma mais intensa o desejo em ter uma liderança mais transformacional do que propriamente à realidade do exercício da liderança nos resorts.

É importante frisar que os dois estilos não são excludentes. Segundo Bass (2008) os dois estilos de liderança são duas dimensões correlacionadas positivamente e que a liderança transformacional acrescenta os efeitos da liderança transacional. A diferença é que na liderança transformacional o líder trabalha mais com a moral e a maturidade do colaborador, fazendo com que esse internalize o querer fazer, sem a correspondente troca de interesses.

Mediante os resultados obtidos dos estilos de liderança praticados nos resorts pela visão dos líderes e liderados, através das análises de frequência, foi possível estabelecer uma comparação de ambas as visões, conforme demonstra as Tabelas 6 e 7.

\begin{tabular}{|l|l|l|l|l|}
\hline Visão & Raramente \% & $\begin{array}{l}\text { Algumas } \\
\text { Vezes \% }\end{array}$ & Frequentemente \% & Valores ausentes \% \\
\hline Líderes & 6,53 & 13,57 & 73,72 & 6,16 \\
\hline Liderados & 21,46 & 21,30 & 54,10 & 3,12 \\
\hline
\end{tabular}

Tabela 6 - Comparação das visões de líderes e liderados sobre o estilo de liderança transformacional Fonte: dados da pesquisa.

A Tabela 6 mostra que 73,72\% dos líderes frequentemente utilizam os atributos da liderança transformacional, transformando este estilo o predominante em sua visão. Ao passo que $54,10 \%$ dos respondentes afirmam que seus líderes frequentemente utilizam os atributos da liderança transformacional, transformando este estilo o predominante em ambas as visões, sendo que em percentual menor pelos liderados. A Tabela 7 apresenta a comparação das visões sobre o estilo transacional. 


\begin{tabular}{|l|l|l|l|l|}
\hline Visão & Raramente \% & $\begin{array}{l}\text { Algumas } \\
\text { Vezes \% }\end{array}$ & Frequentemente \% & Valores ausentes \% \\
\hline Líderes & 31,46 & 18,69 & 44,54 & 5,29 \\
\hline Liderados & 32,87 & 21,64 & 42,83 & 2,64 \\
\hline
\end{tabular}

Tabela 7 - Comparação das visões de líderes e liderados sobre o estilo de liderança transacional Fonte: dados da pesquisa.

Observa-se que $44,54 \%$ dos líderes frequentemente utilizam os atributos da liderança transacional, ao passo que $42,83 \%$ dos respondentes afirmam que seus líderes frequentemente utilizam os atributos da liderança transacional. Estes números, comparados ao resultado dos atributos da liderança transformacional, apresentam-se em menores percentuais.

Mediante a comparação dos resultados, observa-se que o estilo de liderança transformacional foi predominante nas duas visões, sendo que na visão dos líderes apresentou-se 19,6\% maior que na visão dos liderados. Esta diferença, embora represente o mesmo estilo de liderança no resultado geral, pode sugerir uma divergência de visões entre os dois grupos pesquisados, ou seja, o líder não se percebe do mesmo modo que seus liderados o percebem.

Brown e Reilly (2008) reconhecem à eficácia de ambas as formas de liderança e concluem que a liderança transformacional, carrega uma forte dimensão moral, estando, portanto associada a uma liderança eficaz e que em tempos de instabilidade foi mais duradoura do que a do modelo transacional.

\subsection{Pesquisa qualitativa}

A técnica utilizada para análise dos dados da pesquisa qualitativa foi o Focus Group. Foram duas reuniões. Uma com mulheres, que ocorreu no dia 02 de Maio de 2012 em um Hotel localizado na cidade de São Paulo. Outra com os homens, que ocorreu no dia 15 de Maio de 2012. O número de participantes em cada reunião variou de 5 a 7 pessoas. Os participantes escolhidos são formadores de opinião e exercem diversas funções no segmento do Turismo e Hotelaria, conforme demonstra a Tabela 8 . 


\begin{tabular}{|l|c|c|c|}
\hline Categoria / Gênero & Feminino & Masculino & TOTAL \\
\hline Gerente de Hotel & 2 & 3 & 5 \\
\hline Consultor Hoteleiro & 1 & 1 & 2 \\
\hline $\begin{array}{l}\text { Diretor de Turismo } \\
\text { Setor Público }\end{array}$ & 1 & 0 & 1 \\
\hline $\begin{array}{l}\text { Diretor / Coordenador } \\
\text { Acadêmico Curso de } \\
\text { Hotelaria de }\end{array}$ & 1 & 0 & 1 \\
\hline $\begin{array}{l}\text { Diretor } \\
\text { Administradora }\end{array}$ & 0 & 5 & 10 \\
\hline Hoteleira & 5 & & \\
\hline TOTAL & $8-$ CotaL & & 1 \\
\hline
\end{tabular}

Tabela 8 - Composição das reuniões

Fonte: dados da pesquisa.

Pode-se observar que as reuniões contemplaram a quantidade de participantes recomendada pela literatura para esta técnica, bem como a abrangência e diversidade dos cargos e funções dos formadores de opinião no segmento pesquisado.

Os resultados da pesquisa quantitativa foram apresentados aos dois grupos no inicio das reuniões para serem debatidos de acordo com a experiência profissional de cada um dos participantes.

Para melhor apresentar os resultados de ambos os grupos focais, estabeleceu-se uma comparação com os principais pontos debatidos.

Embora ambos os grupos concordem em alguns aspectos relacionados às questões do roteiro do Focus Group, ficou evidenciado a diferença de visão e percepção entre os gêneros, bem como as contradições em relação ao resultado da pesquisa quantitativa.

Entre as opiniões semelhantes entre os dois grupos destacam-se:

- Ambos acreditam que o estilo transacional é o mais praticado nos hotéis e resorts do Brasil. 
- Ambos acreditam que o estilo transformacional é o ideal para a hotelaria.

- Ambos citaram o tipo de administração como fator determinante para o estilo de liderança.

- Ambos comentaram que a alta diretoria influencia muito no estilo de liderança do demais gestores.

- Ambos acreditam que o líder não enxerga suas falhas e por isso acredita ter o estilo transformacional, mas que isso não reflete a realidade.

- Ambos acreditam que os liderados podem ter sido influenciados em sua opinião ao responder a pesquisa, pela vontade de que seus líderes possuam os atributos da liderança transformacional, muito mais do que pela realidade em que eles vivem.

\subsection{Comparação dos resultados da Pesquisa Quantitativa e Qualitativa}

Ao comparar os dados da pesquisa quantitativa e qualitativa, foi possível observar algumas discrepâncias em relação aos resultados, conforme apresenta o quadro 3:

\begin{tabular}{|l|l|}
\hline \multicolumn{1}{|c|}{ Pesquisa Quantitativa } & \multicolumn{1}{|c|}{ Pesquisa Qualitativa } \\
\hline $\begin{array}{l}\text { Estilo predominante praticado nos resorts é o } \\
\text { Transformacional }\end{array}$ & $\begin{array}{l}\text { Estilo predominante praticado nos resorts é o } \\
\text { Transacional }\end{array}$ \\
\hline $\begin{array}{l}\text { Estilo predominante nos resorts pela visão dos } \\
\text { líderes é o Transformacional }\end{array}$ & $\begin{array}{l}\text { Estilo predominante nos resorts pela visão } \\
\text { dos líderes é o Transacional }\end{array}$ \\
\hline $\begin{array}{l}\text { Estilo predominante nos resorts pela visão dos } \\
\text { liderados é o Transformacional }\end{array}$ & $\begin{array}{l}\text { Estilo predominante nos resorts pela visão } \\
\text { dos liderados é o Transacional }\end{array}$ \\
\hline
\end{tabular}

Quadro 3 - Discrepâncias entre as pesquisas quantitativa e qualitativa Fonte: dados da pesquisa.

O Quadro 3 demonstra que houveram discrepâncias relacionadas ao objetivo geral da pesquisa, bem como dos objetivos específicos. As possíveis causas destes resultados distintos foram levantadas na pesquisa qualitativa pelos formadores de opinião. Para eles, os respondentes líderes não enxergam suas deficiências e acreditam realmente ter o estilo ideal 
de liderança, ao passo que os respondentes liderados podem ter respondido de acordo com os seus desejos e não com a verdade em si.

Um fator que corrobora com esta conclusão e que pode ser considerado como um possível responsável pela discrepância no resultado da pesquisa quantitativa é a desejabilidade social. Segundo Ribas, Moura e Hutz (2004), a desejabilidade social reflete uma propensão por parte das pessoas a dar respostas consideradas como socialmente mais aceitáveis e a negar associação pessoal com opiniões ou comportamentos considerados socialmente desabonadores.

Essa tendência pode colocar em risco a validade da pesquisa e deve ser controlada pelo pesquisador. Distorções nas respostas resultantes da desejabilidade social podem estar associadas a diferentes processos e ter diferentes origens, tais como: características pessoais; condições e modos de aplicação de instrumentos de pesquisa; respostas tendenciosas que são dadas inadvertidamente ou inconscientemente pelos participantes; fraude, ou seja, respostas distorcidas propositalmente pelos participantes com o objetivo de manipular a imagem pessoal que é oferecida. Distorções relacionadas à desejabilidade social podem colocar em risco a validade de pesquisas quantitativas, especialmente quando estas envolvem questionários auto administrados. (RIBAS; MOURA; HUTZ, 2004).

No caso da presente pesquisa, este fator pode explicar a diferença de opinião dos líderes e liderados participantes ao responderem o questionário MLQ, fazendo com que seja considerado como válido o resultado da pesquisa qualitativa para responder aos objetivos do presente artigo.

\section{Considerações Finais}

O objetivo principal deste artigo foi identificar e analisar os estilos de liderança praticados nos resorts do Brasil. Para o alcance deste objetivo, inicialmente, fez-se necessário à explicitação e discussão de diferentes conceitos que abordam o tema liderança. Em seguida, a revisão da literatura acerca do tema verificou a evolução das teorias de liderança envolvendo as teorias dos traços, estilo de liderança, teoria contingencial e da nova liderança, sendo que esta última 
contemplou a abordagem da Liderança Transacional e Liderança Transformacional, escolhidas para pesquisa do presente artigo.

O resultado da pesquisa quantitativa indica que o estilo predominante nos resorts do Brasil é o Transformacional, o que pode ser considerado positivo, já que segundo Brownel (2010) é o estilo mais adequado para a indústria hoteleira. Bass (2008) também afirma que a liderança transformacional é a única modalidade de liderança capaz de propiciar aos seguidores um desempenho extraordinário, buscando elevar a consciência do grupo e da empresa, favorecendo a evolução das pessoas e alinhando as expectativas individuais e organizacionais.

Em relação aos objetivos específicos, os resultados mostraram que o estilo de liderança predominante nos resorts na visão dos líderes é o Transformacional com 73,7\%. Já na visão dos liderados, o estilo de liderança predominante é o mesmo, porém com uma porcentagem menor de 54,1\%. Embora os resultados tenham identificado o mesmo estilo de liderança nas duas visões, é possível afirmar que os liderados não enxergam seus líderes do mesmo modo que os mesmos se percebem. Os atributos da liderança transformacional pela opinião dos liderados são vistos em menor escala que a dos líderes, aproximando-se do estilo transacional, identificado como predominante pelos formadores de opinião na pesquisa qualitativa.

A mesma revelou que os especialistas do Focus Group não concordam com os resultados obtidos na pesquisa quantitativa em relação ao estilo de liderança praticado nos resorts do Brasil. Para eles, o estilo predominante é ainda o Transacional, embora concordem que o Transformacional seja o ideal para o segmento. Ainda em relação aos estilos, os grupos feminino e masculino concordaram com o fato de que a maioria dos líderes se enxergam melhores do que realmente são. Isto pode ter contribuído para o resultado da pesquisa de campo, mas ressaltam que tal resultado não reflete a realidade dos resorts.

Sendo assim, com relação ao objetivo geral e objetivos específicos do artigo, os procedimentos metodológicos identificaram uma opinião divergente em relação ao estilo de liderança predominante nos resorts e nas comparações entre as visões dos líderes e liderados.

Para responder ao objetivo geral, enquanto os resultados da pesquisa quantitativa identificaram o estilo de liderança Transformacional como predominante, o resultado da pesquisa qualitativa contestou tais resultados, afirmando não representar a realidade por eles 
percebida. Esta discrepância entre os resultados das duas pesquisas levou à busca de um entendimento maior acerca das possíveis causas, chegando à conclusão de que a desejabilidade social pode explicar a diferença de opinião dos líderes e liderados participantes da pesquisa quantitativa, fazendo com que seja considerado como válido o resultado da pesquisa qualitativa para responder o objetivo geral do presente artigo, bem como dos objetivos específicos. Esta seria a visão da literatura perante os resultados.

Além deste fator, é importante mencionar que o segmento da hotelaria sofre com a falta de mão de obra qualificada e de líderes capacitados a motivar suas equipes a desempenhar a excelência nos serviços prestados pertinentes aos resorts. Deste modo, seria contraditório e prematuro concluir que a liderança hoje já pode ser considerada transformacional, visto que a realidade não se apresenta desta forma. O que se observa é um segmento ainda em evolução na questão relacionada à Gestão de Pessoas, pois pouco se investe nesta área. Esta visão acerca dos resultados pode ser inferida por meio das análises dos pesquisadores, bem como dos resultados da pesquisa qualitativa com os relatos dos formadores de opiniões do segmento. Sendo assim, o estilo de liderança predominante praticado nos resorts do Brasil considerado na presente pesquisa é o Transacional.

\section{Referências}

ALBUQUERQUE, L. G.; LEITE, N. P. A estratégia de Gestão de Pessoas como ferramenta do desenvolvimento organizacional. Revista Ibero-americana de Estratégia: RIAE, São Paulo, v. 9, n. 1, p. 31-53, 2010.

ALMEIDA, C. M. A. A Influência da espiritualidade nos estilos de liderança. Dissertação (Mestrado em Administração)-Universidade Presbiteriana Mackenzie, São Paulo, 2004.

ASSOCIAÇÃO BRASILEIRA DE RESORTS. Resorts Brasil. 2011. Disponível em: <www.resortsbrasil.com.br>. Acesso em: 31 mar. 2011.

BASS, B. M. Handbook of leadership: survey of theory and research. New York: Free Press, 1990.

BASS, B. M. The bass handbook of leadership: theory, research, managerial applications. 4. ed. New York: Free Press, 2008.

BENNIS, W., NANUS, B. Líderes - estratégias para assumir a verdadeira liderança. São Paulo: Harba, 1988. 
BENTO, A. Estilos de liderança dos líderes escolares da região autônoma da madeira. In: Costa, J.; Neto-Mendes, A.; Ventura, A. (Org.). Actas do V simpósio sobre organização e gestão escolar trabalho docente e organizações educativas. Aveiro: Universidade de Aveiro, 2008. p. 145-157. 1 CDROM. ISBN 978-972-789-281-5.

BERGAMINI, C. W. Liderança administração do sentido. 1. ed. São Paulo: Atlas, 1994. p. 234.

BERGAMINI, C. W. Psicologia aplicada à administração de empresas: psicologia do comportamento organizacional. 4. ed. São Paulo: Atlas, 2008. p. 197.

BIDO, D. S. et al. Mensuração com indicadores formativos nas pesquisas em administração de empresas: como lidar com a multicolinearidade entre eles? Administração: Ensino e Pesquisa, Rio de Janeiro, v. 11, n. 2, p. 245-69, abr.-jun. 2010.

BRASIL. Portal da Copa. Grandes números. 2012. Disponível em: <http://www.copa2014.gov.br/ptbr/sobre-a-copa/grandes-numeros>. Acesso em: 20 abr. 2012.

BRYMAN, A. Handbook de estudos organizacionais. Leadership and organizations. 3. v. São Paulo: Atlas, 2004.

BROWN, F. W.; REILLY, M. D. The myers-briggs type indicator. Journal Of Management Development, Montana, USA, v. 28, n. 10, p. 916-932, 2 out. 2008. Disponível em: <www.emeraldinsight.com/0262-1711.htm>. Acesso em: 30 set. 2010.

BROWNELL, J. Leadership in the service of hospitality. Cornell Hospitality Quarterly, Ithaca, v. 5, n. 3, p. 363-378, 21 maio 2010.

BURNS, J. M. Leadership. New York: Harper \& Row Publishers, 1978.

CARVALHO, N. L. N.; SILVA, A. B.; ZAGO, C. C.. Fatores de Influência no Desenvolvimento de Competências Gerenciais em Hotéis e Pousadas. Revista Turismo, Visão e Ação - Eletrônica. Balneário de Camboriú: vol. 13 - nº 2 - p. 201-219 / mai-ago, 2011

CLARK, R. A.; HARTLINE, M. D.; JONES, K. C. The Effects of Leadership Style on Hotel Employees' Commitment to Service Quality. Cornell Hospitality Quarterly, Ithaca, v. 50, n. 2, p. 209-231, 24 abr. 2008.

COVEY, S. R. Liderança baseada em princípios. 5. ed. Rio de Janeiro: Campus, 2002. p. 384.

CRESWELL, J. W. Projeto de pesquisa: método qualitativo, quantitativo e misto. 3. ed. Porto Alegre: Artmed, 2010. p. 296.

DUTRA, N. H. Estilos de liderança em evidência na indústria de calçados de médio porte da cidade de Franca - SP. 2006. Dissertação (Mestrado em Administração)-Centro Universitário de Franca, Franca, 2006.

FREITAS, C. M. F. Estudo da motivação e da liderança na indústria hoteleira da RAM. 2006. 140 f. Dissertação (Mestrado em Administração)-Universidade da Madeira, Funchal, 2006.

GIL, A. C. Como elaborar projetos de pesquisa. 5. ed. São Paulo: Atlas, 2010. p. 184.

GONÇALVES, M. N. C. Estilos de liderança: um estudo de auto-percepção de enfermeiros gestores. 2008. 129 f. Dissertação (Mestrado)-Universidade Fernando Pessoa, Porto, 2008. 
INSTITUTO BRASILEIRO DE GEOGRAFIA E ESTATÍSTICA - IBGE. Pesquisa de serviços em hospedagem 2011. 2012. Disponível em: <http://www.ibge.gov.br/home/estatistica/economia/comercioeservico/psh/2011_todas_regioes/default .shtm >. Acesso em: 19 abr. 2012.

INSTITUTO BRASILEIRO DE GEOGRAFIA E ESTATÍSTICA - IBGE. Economia do turismo. Uma perspectiva macroeconômica 2003-2007. 2010. Disponível em: < http://www.ibge.gov.br/home/estatistica/economia/industria/economia_tur_20032007/default.shtm >. Acesso em: 19 abr. 2012.

KOTTER, J. P. O fator liderança. São Paulo: Makron Books, 1992.

LIMONGI-FRANÇA, A. C.; ARELLANO, E. B. Liderança, poder e comportamento organizacional. In: FLEURY, M. T. L. (org.). As pessoas na organização. São Paulo: Gente, 2002. p. 259-269.

OLIVEIRA, M; FREITAS, H. Focus Group, pesquisa qualitativa: resgatando a teoria, instrumentalizando o seu planejamento. RAUSP. São Paulo, v. 33, n. 3, p. 83-91, jul-set. 1998.

RIBAS JR, R. C.; MOURA, M. L. S.; HUTZ, C. S. Adaptação brasileira da escala de desejabilidade social de Marlowe-Crowne. PEPSIC, v. 3, n. 2, p. 83-92, 2004. Disponível em: $<$ http://pepsic.bvsalud.org/scielo.php?script=sci_arttext\&pid=S1677-

04712004000200003\&lng=pt\&nrm=iso\&tlng=pt $>$. Acesso em: 9 jul. 2012.

SMITH, P. B. Liderança, organizações e cultura: modelo da administração do evento. São Paulo: Pioneira, 2005.

STEFANO, S. R. et. al. Satisfação da qualidade de vida no trabalho com relação aos fatores biopsicossociais e organizacionais: um estudo comparativo entre docentes das universidades pública e privada. Revista Gerenciais. São Paulo, v. 5, p. 35-44, 2006.

VERGARA, S. C. Gestão de pessoas. São Paulo: Atlas, 2000.

Recebido em: 29/10/2012 ( $1^{\text {a }}$ versão) $04 / 11 / 2013$ ( $2^{\mathrm{a}}$ versão)

Aprovado em: 05/11/2013 